\title{
Capacity Development Analysis of Medical Tourism in Hospitals of Tehran, Iran
}

\author{
Moslem Ghasemi ${ }^{*}$, Ali Movahed ${ }^{1}$, Samira Motaghi' ${ }^{2}$, Samaneh Kadkhodaei ${ }^{1}$ \\ ${ }^{1}$ Department of Geography and Tourism Planning, Kharazmi University, Tehran, Iran \\ ${ }^{2}$ Department of Economics, Payam-e-Noor University, Tehran, Iran
}

Corresponding Author: Moslem Ghasemi, PhD, Assistant Professor, Department of Geography and Tourism Planning, Kharazmi University, Tehran, Iran. Tel: +98-9104520459, Email: moslem.ghasemi@khu.ac.ir

Received June 24, 2020; Accepted September 23, 2020; Online Published November 14, 2020

\begin{abstract}
Introduction: One of the new tourism capacities of Iran in recent years is medical tourism, which has grown significantly. Tehran is one of the most important cities in the Middle East in the field of medical tourism. This study intends to analyse medical tourism capacity development in Tehran hospitals from international tourists' perspective to identify the most efficient factors in medical tourism capacity development in Tehran hospitals.

Methods: The research type is applied and the research method is descriptive-analytical. The research sample is the international medical tourists entering five major Tehran hospitals having the International Patient Department license (IPD), in which 154 samples were selected randomly from a total sample society of 258 using Cochran formula.

Results: The results show that the priority areas of medical tourism capacity development in Tehran are low medical costs, optimal quality of services, easy access to medical services and physicians' knowledge, respectively.

Conclusion: In general, regarding the studied variables, it can be concluded that there is a good opportunity for medical tourism capacity development in Tehran from the international tourists' viewpoint.

Keywords: Delivery of Health Care, Medical Tourism, Hospitals, Iran
\end{abstract}

Citation: Ghasemi M, Movahed A, Motaghi S, Kadkhodaei S. Capacity development analysis of medical tourism in hospitals of Tehran, Iran. Int J Travel Med Glob Health. 2020;8(4):165-169. doi:10.34172/ijtmgh.2020.28.

\section{Introduction}

Tourism is now a global industry involving hundreds of millions of people in international as well as domestic travel each year. ${ }^{1}$ One of the new tourism capacities in recent years is medical tourism which has grown significantly especially in Iran. Medical tourism, primarily a late twentieth-century phenomenon, is said to have recently and rapidly boomed. Medical tourism is said to have grown explosively since the late 1990s with thousands of patients moving to countries such as India, Thailand, and Mexico, in search of medical care usually deemed too expensive, inadequate, or unavailable at home. Ironically the first account of what has become a phenomenon imbued with capitalism, entitlement, individualism, and selffulfilment was of Cuba. ${ }^{2}$ Yet, in the last two decades a form of 'reverse globalisation' has occurred with patients from more developed countries travelling for medical care to less developed countries, for a combination of reasons involving cost, access, service, and quality, overturning implicit notions of the territoriality of health care. ${ }^{3}$ Traditionally, consumers from all continents and forms of health systems have travelled abroad for their healthcare to avoid waiting lists or access state-of-the-art techniques and receive better aftercare services. ${ }^{4}$ With the rise of more affordable cross-border travel, rapid technological developments (encompassing both surgical techniques as well as the increased volume and access to 'quality' medical information on the internet), these services have been further facilitated and made available to a wider segment of the consumer market. ${ }^{5}$

Moreover, it is emphasized that within the health tourism arena, medical tourism is among the fastest-growing sectors, and many countries are now making legal and practical plans to serve it. Reduced transportation costs, higher incomes, knowledge, and technology transfer, and competitive prices all favour travel to distant countries for medical reasons. Gupta $^{6}$ defines medical tourism as the provision of costeffective medical care for patients in collaboration with the tourism industry. The process is usually facilitated by the private medical care sector, but involves both the private

Copyright $\odot 2020$ The Author(s). This is an open-access article distributed under the terms of the Creative Commons Attribution License (http:// creativecommons.org/licenses/by/4.0), which permits unrestricted use, distribution, and reproduction in any medium, provided the original work is properly cited. 
and public sectors of the tourism industry. Medical tourists can take advantage of having medical surgery or treatment while enjoying a stay in one of the world's popular tourist destinations. Connell ${ }^{7}$ characterizes medical tourism as a popular cultural phenomenon whereby people travel long distances to obtain medical, dental, and surgical services while vacationing. The medical procedures they obtain include not only elective surgeries such as cosmetic and dental operations but also more complex surgeries that require specialist knowledge and technology. ${ }^{8}$ Medical check-ups and health screening are preventive medical services that are also considered to fall within the scope of medical tourism.

Capacity building in healthcare is an important element that can be effective in improving health promotion ${ }^{9}$ and can play a prominent role in the performance of the health system. ${ }^{10}$ Capacity analysis began from the individual level up to the social level. In each mentioned dimension, there are various variables. In the destination dimension, there are variables such as (1) political situation (2) economic conditions (3) regulatory standards (4) local urban attraction and (5) cultural integration while in the organizational and institutional dimension, the variables contain: (1) buildings and facilities (2) infrastructures and equipment (3) quality of services and facilities (4) human resources (5) medical credit (6) reputation (7) commitment and (8) education.

Moreover, in the tourist dimension the variables include: (1) motivation (2) cost (3) reputation of the hospital (4) specialist physicians (5) quality of care (6) knowledge and (7) privacy. ${ }^{11}$ It is also crucial to emphasize that social, cultural, political, and economic dimensions generally play an important role in the sustainable development of the regions, especially in the process of destination selection and the tourists' decision. Therefore, the conceptual model of capacity development of medical tourism used in this study is based on the dimensions and variables mentioned above (Figure 1).

In addition, several factors that are deemed important by the patients are considered unimportant by professionals. This indicates problems with health professionals' understanding

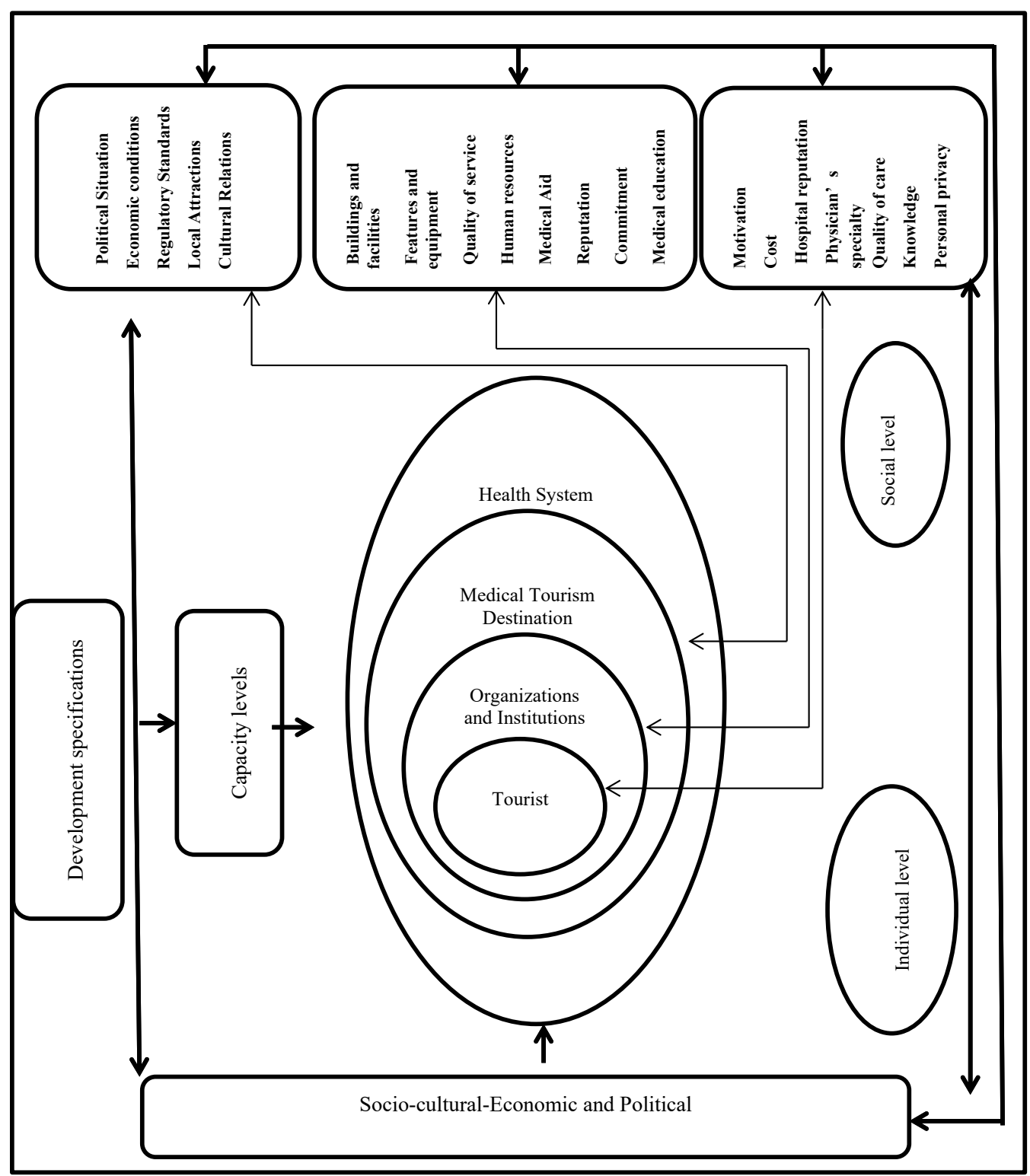

Figure 1. The Novel Conceptual Model for Capacity Development of Medical Tourism. ${ }^{11}$ 
and assessment of the consumer decision process in international healthcare facility choice. The major points that professionals and patients differ on can be summarized as follows: political and economic stability, regulations, and legal framework as well as ease of access. ${ }^{12}$

The results of a study to determine the factors influencing the development of medical tourism in Hong Kong revealed that policies and regulations, government support, costs, capacity problems, and the healthcare needs of the local community are the main barriers to the development of such tourism. Several strategies for lifting these barriers are suggested, such as new promotional activity policies, government action to encourage investment in the medical tourism market, and cooperative efforts by the hospitality sector and medical institutions to develop medical tourism products. ${ }^{13}$

Iran and in particular Tehran metropolis having diverse tourist attractions alongside high-quality hospitals can strongly compete with other medical tourism destinations in the Middle East region if its medical tourism capacity development components are known and identified well; hence, this research aims to analyse the medical tourism capacity development elements of Tehran metropolis from international tourists' point of view based on the Novel Conceptual Model for Capacity Development of Medical Tourism ${ }^{11}$ to see what the major medical tourism development capacity areas are in Tehran metropolis and how these components could end in boosting medical tourism in Tehran metropolis.

\section{Methods}

This study is applied research. The method used in this study is descriptive-analytical and was surveyed using a 1-5 point Likert scale questionnaire where scale 3 means average response, thus the mean value should be higher than three to accept the One sample T-test. The statistical population under study was gathered from incoming international medical tourists from five hospitals of Tehran having the International Patient Department (IPD) license including Pars, Mehr, Bahman, Amir-e-Alam, and Moheb-e-Vanak hospitals. It should be mentioned that the method of choosing these hospitals is purposive sampling based on the researcher's knowledge about the well-known IPD hospitals of Tehran, Iran. According to the total number of incoming international medical tourists to the five target hospitals of Tehran within the three months of spring 2018 when the number of tourists was 258 and then based on Cochran's formula at 95\% significance level, 154 questionnaires were distributed among tourists in these five hospitals using a simple random sampling method. One hundred and fifty valid questionnaires were sent back to the researchers and the researchers began to test the following research hypotheses to fulfil the research goal. To analyse the gathered data, one sample T-test, Cochran's formula, and Cronbach's alpha coefficient were used in SPSS version 26 and Excel version 2019 software's environment.

\section{Research Hypotheses}

1. The medical knowledge of physicians affects medical tourism development in Tehran positively.

2. The international infrastructure standards of medical tourism is one of the important factors for tourism development in Tehran.

3. Reducing medical costs plays a vital role in the development of medical tourism in Tehran.

In this research, based on the conceptual framework a questionnaire having 8 dimensions and 27 factors was designed based on a 1-5 Likert scale, and the reliability and validity of the questionnaire were evaluated using Cronbach's alpha method by conducting a pilot study of the distribution of 25 questionnaires among tourists. Accordingly, since the value for Cronbach's alpha was 0.85 , the questionnaire was considered reliable and valid.

\section{Results}

The demographic information of respondents is presented in Table 1 . The total number of respondents is 150 , of which $60 \%$ of the total population is male and $40 \%$ of the total population is female. They ranged in age from 21 to 63 years old which are mostly in the age group of 31 to 49 years old. Moreover, the descriptive findings obtained from the survey of respondents' country of origin indicate that the largest number of tourists who responded to the survey questionnaire were of Iraqi nationality.

The questionnaire is designed based on a 5-point Likert scale, therefore, the minimum Mean value of 3 is considered for acceptance of the hypothesis. The result of this test for each hypothesis is presented in the following table

Hypothesis 1. It seems that the medical knowledge of physicians is one of the main areas of medical tourism development in Tehran.

According to Table 2, the mean value (3.78) is higher than 3 since the significance level ( $P$ value $)$ is less than 0.001 and the

Table 1. The Demographic Characteristics of the Respondents

\begin{tabular}{lll}
\hline Variable & No. & Percent \\
\hline Gender & 90 & 60 \\
Male & 60 & 40 \\
Female & 150 & 100 \\
Total & & \\
Age & 0 & 0 \\
Lower than 20 & 43 & 28 \\
21 to 30 & 75 & 50 \\
31 to 49 & 33 & 22 \\
50 to 63 & 150 & 100 \\
Total & & 18 \\
Nationality & 27 & 72 \\
Bahrain & 108 & 2 \\
Iraq & 3 & 8 \\
Syria & 12 & \\
Qatar & 150 & 100 \\
Total & & \\
\hline
\end{tabular}


mean difference $(0.78)$ is between $95 \%$ confidence interval of the difference of 0.69 and 0.87 which confirm the first hypothesis meaning that medical knowledge of physicians is one of the main areas of medical tourism development in Tehran from international tourists' point of view.

Hypothesis 2. It seems that having the international infrastructure standards of medical tourism is one of the important factors for tourism development in Tehran. According to Table 3, the mean value (4.41) is higher than 3 since the significance level ( $P$ value) is less than 0.001 and the mean difference (1.41) is between $95 \%$ confidence interval of the difference of 1.3 and 1.51 which all in all justify the second hypothesis showing that having the international infrastructure standards of the medical tourism is one of the important factors for the tourism development in Tehran from international tourists' perspective.

Hypothesis 3. It seems that reducing medical costs plays a vital role in the development of medical tourism in Tehran.

According to Table 4, the man value (4.60) is higher than 3 since the significance level ( $P$ value) is less than 0.001 and the mean difference (1.60) is between $95 \%$ confidence interval of the difference of 1.33 and 1.87 which in general affirm the third hypothesis demonstrating that reducing medical costs plays a vital role in the development of medical tourism in Tehran from international tourists' viewpoint.

Hence, considering the results of inferential statistics affirming the research hypotheses, the capacity development of medical tourism in Tehran hospitals is analysed from tourists' perspective based on the novel conceptual model for capacity development of medical tourism ${ }^{11}$ and it is proved that the key factors presented in this model play a determinant role in capacity development of medical tourism in Tehran hospitals from tourists' viewpoint in a way that "low medical costs" is the most important factor since "having the international infrastructure standards of the medical tourism" ranked the second important factor while for tourists the "Physician Knowledge" is of the lowest importance.

\section{Discussion}

Various countries like Thailand, Malaysia, India, etc are promoting medical tourism aggressively. The key competitive advantages of India in medical tourism stem from the following terms: low-cost advantage, strong reputation in the advanced healthcare segment (cardiovascular surgery, organ transplants, eye surgery, etc), and the diversity of tourist destinations available in the country which affirms the results of the current study. In contrast, other research works argued that the underlying success factor for the sustainable competitiveness of a healthcare destination is neither price nor medical quality, but rather high quality and patientcentered personal services which are the key to the success and sustainability of medical tourism destinations It is found that, while a low price might initiate interest in medical treatment abroad, but return visits are built on profound patient satisfaction, and even bonding, to doctors and nurses. Therefore, these studies discuss that successful health destinations need to provide foreign patients unexpectedly pleasant experiences through organisational innovations and service quality based on superior patient-doctor-nurse relationship. ${ }^{14}$ However, unless properly managed and regulated on the policy side, the financial benefits of medical

Table 2. One Sample T-test Results for Hypothesis 1

\begin{tabular}{|c|c|c|c|c|c|c|}
\hline \multicolumn{7}{|c|}{ One-Sample Test } \\
\hline & \multicolumn{6}{|c|}{ Test Value $=3$} \\
\hline & \multirow{2}{*}{$t$} & \multirow{2}{*}{$d f$} & \multirow{2}{*}{$P$ Value } & \multirow{2}{*}{ Mean Difference } & \multicolumn{2}{|c|}{$95 \%$ Confidence Interval of the Difference } \\
\hline & & & & & Lower & Upper \\
\hline Hypothesis 1 & 17.24 & 149 & $<0.001$ & 0.78 & 0.69 & 0.87 \\
\hline
\end{tabular}

$\mathrm{N}=150$, Mean $=3.7829$, Standard deviation $=0.5560$, Standard error of the mean $=0.4540$

Table 3. One Sample T-test Results for Hypothesis 2

\begin{tabular}{|c|c|c|c|c|c|c|}
\hline \multicolumn{7}{|c|}{ One-Sample Test } \\
\hline & \multicolumn{6}{|c|}{ Test Value $=3$} \\
\hline & \multirow{2}{*}{$t$} & \multirow{2}{*}{$d f$} & \multirow{2}{*}{$P$ Value } & \multirow{2}{*}{ Mean Difference } & \multicolumn{2}{|c|}{$95 \%$ Confidence Interval of the Difference } \\
\hline & & & & & Lower & Upper \\
\hline Hypothesis 1 & 26.65 & 149 & $<0.001$ & 1.41 & 1.30 & 1.51 \\
\hline
\end{tabular}

$\mathrm{N}=150$, Mean $=4.41$, Standard deviation $=0.64$, Standard error of the mean $=0.05$

Table 4. One Sample T-test Results for Hypothesis 3

\begin{tabular}{|c|c|c|c|c|c|c|}
\hline \multicolumn{7}{|c|}{ One-Sample Test } \\
\hline & \multicolumn{6}{|c|}{ Test Value $=3$} \\
\hline & \multirow{2}{*}{$t$} & \multirow{2}{*}{$d f$} & \multirow{2}{*}{$P$ Value } & \multirow{2}{*}{ Mean Difference } & \multicolumn{2}{|c|}{ 95\% Confidence Interval of the Difference } \\
\hline & & & & & Lower & Upper \\
\hline Hypothesis 1 & 11.77 & 149 & $<0.001$ & 1.60 & 1.33 & 1.87 \\
\hline
\end{tabular}

$\mathrm{N}=150$, Mean $=4.60$, Standard deviation $=1.66$, Standard error of the mean $=0.13$ 
tourism for health systems may come at the expense of access to and use of health services by local consumers. Additionally, the key concerns facing the industry include the absence of government initiative, lack of a coordinated effort to promote the industry, no accreditation mechanism for hospitals, and the lack of uniform pricing policies and standards across hospitals. ${ }^{15}$ Finally, it should be noticed that governments and industry players should do well to remember that health is wealth for both foreign and local populations. ${ }^{16}$

\section{Conclusion}

Tehran, as one of the most important gateways of tourism in Iran with high tourism capabilities, can play an important role in medical tourism. Medical tourists consider the international standards of modern infrastructure and equipment to be effective in tourism development. Therefore, in order to develop medical tourism in Tehran, in addition to low medical costs and high quality and optimum service provision, infrastructure and equipment must be considered and complied with the global standards. The research noted that Tehran has the capacity to develop medical tourism, so that many foreign tourists, especially in neighbouring countries, are interested in treatment in Tehran hospitals, Iran.

\section{Recommendations}

Based on the research findings, medical tourism in Tehran hospitals has some weaknesses; as a result, it is recommended:

- Public and foreign language education for hospital staff

- Guidance and proper treatment of the patient upon arrival in the country

- Holding up to date workshops for hospital staff

- Establishment of medical tourism departments in travel agencies

- Serious encounter with medical tourism speculators

- $\quad$ Banking and monetary facilitation for medical tourists

\section{Authors' Contributions}

All authors contributed equally to the preparation of this paper.

\section{Conflict of Interest Disclosures}

The authors declare no conflict of interest in their research.

\section{Ethical Approval}

This study was approved by Kharazmi University Ethics Committee, Tehran, Iran.

\section{Funding/Support}

None.

\section{References}

1. Mason P. Tourism Impacts, Planning and Management. Routledge; 2015.

\section{Research Highlights}

What Is Already Known?

We know the key competitive advantages of medical tourism development factors in the World.

\section{What This Study Adds?}

The main areas of medical tourism development in Tehran, according to tourists' point of view, are:

- the ease of acceptance and easy access to services,

- low medical costs, high quality,

- desirable standard of medical centers in Tehran,

- tourist attractions in Tehran and the presence of experts and physicians.

2. Goodrich JN, Goodrich GE. Health-care tourism--an exploratory study. Tour Manag. 1987;8(3):217-222. doi:10.1016/02615177(87)90053-7.

3. Connell J. Contemporary medical tourism: conceptualisation, culture and commodification. Tour Manag. 2013;34:1-13. doi:10.1016/j.tourman.2012.05.009.

4. Goodrich JN. Socialist Cuba: a study of health tourism. J Travel Res. 1993;32(1):36-41. doi:10.1177/004728759303200106.

5. EhrbeckT, Guevara C, Mango PD. Mapping the Market for Medical Travel. The McKinsey Quarterly; 2008.

6. Gupta A. Medical tourism and public health. People's Democracy. 2004;27(19).

7. Connell J. Medical tourism: sea, sun, sand and ... surgery. Tour Manag. 2006;27(6):1093-1100.doi:10.1016/j.tourman.2005.11.005.

8. Singh PK. Medical Tourism: Global Outlook and Indian Scenario. New Delhi: Kanishka Publishers; 2008.

9. Hawe P, Potvin L. What is population health intervention research? Can J Public Health. 2009;100(1):Suppl I8-14. doi:10.1007/ bf03405503.

10. Brown L, LaFond A, Macintyre K. Measuring Capacity Building. Chapel Hill, NC: Carolina Population Center, University of North Carolina at Chapel Hill; 2001.

11. Ghasemi M, Movahed A, Kadkhodaei S. A novel conceptual model for capacity development of medical tourism. International Journal of Health Management and Tourism. 2019;4(2):82-95. doi:10.31201/ijhmt.530031.

12. Aydin G, Karamehmet B. Factors affecting health tourism and international health-care facility choice. Int J Pharm Healthc Mark. 2017;11(1):16-36. doi:10.1108/ijphm-05-2015-0018.

13. Heung VCS, Kucukusta D, Song H. Medical tourism development in Hong Kong: an assessment of the barriers. Tour Manag. 2011; 32(5):995-1005. doi:10.1016/j.tourman.2010.08.012.

14. Veerasoontorn R, Beise-Zee R, Sivayathorn A. Service quality as a key driver of medical tourism: the case of Bumrungrad International Hospital in Thailand. International Journal of Leisure and Tourism Marketing. 2011;2(2):140-158. doi:10.1504/ijltm.2011.038886.

15. Dawn SK, Pal S. Medical tourism in India: issues, opportunities and designing strategies for growth and development. Int J Multidiscip Res. 2011;1(3):185-202.

16. Pocock NS, Phua KH. Medical tourism and policy implications for health systems: a conceptual framework from a comparative study of Thailand, Singapore and Malaysia. Global Health. 2011;7:12. doi:10.1186/1744-8603-7-12. 